\title{
LA IRA COMO PASIÓN EN LA CONFIGURACIÓN DE UNA IDENTIDAD FEMENINA
}

\section{ANGER AS PASSION IN THE CONFIGURATION OF A FEMALE IDENTITY}

\author{
Laura Cristina Bonilla Neira \\ UIS - Universidad Industrial de Santander - Colombia ${ }^{1}$
}

\begin{abstract}
RESUMEN: El presente análisis discursivo propone evidenciar la ira como uno de los articuladores pasionales de la identidad de la figura femenina principal de la crónica Golpes de la vida de Lina María Ararat Ospina. Se pretende mostrar cómo actúa el dispositivo pasional en la construcción de la identidad de Gabriela, la enunciadora femenina de la crónica, que narra la historia de vida de una mujer colombiana maltratada por su esposo. En la secuencia específica de la cual parte el análisis Gabriela reacciona frente a la agresión en un acto catalogado como de ira.
\end{abstract}

PALABRAS CLAVE: ira; pasión; discurso; identidad; mujer.

ABSTRACT: This evidence suggests discursive analysis anger as one of the articulators passionate female identity of the actor's main female chronic life Beats Ararat Lina Maria Ospina, have on the social conditions in which they find themselves. This paper shows how the device acts of passion in building the identity of Gabriela, the female enunciating chronicle. This journalistic discourse narrative-descriptive type realizes the life story of a Colombian woman abused by her husband and in the specific sequence of the analysis part, Gabriela reacts against aggression.

KEYWORDS: anger; passion; discourse; identity; woman.

\section{Introducción}

A lo largo del tiempo, la teoría de las pasiones ha sido examinada por diversas disciplinas en las que se destacan la filosofía y la sicología. Cada una ha intentado desde sus diversas corrientes explicar dentro de su propio sistema la nomenclatura variada que ofrece el entramado afectivo. Por ejemplo, el sentimiento como estado durable y ligado estrechamente a las representaciones, la emoción como estado efímero y dinámico, la inclinación como "disposición" que se define como un deseo, el temperamento definido como equilibrio de una mezcla y el carácter que como conjunto es más homogéneo que el temperamento en tanto que se constituye de maneras habituales de sentir y reaccionar ante diversas situaciones (GREIMAS, 1994, p. 80).

Las pasiones han sido separadas del conjunto narrativo al que pertenecen, a pesar de que están dadas y desarrolladas en la existencia narrativa. Pues se considera como un hecho que se sale de lo estrictamente racional. Por lo que diversas disciplinas separan

\footnotetext{
${ }^{1}$ Licenciada en español y literatura de la Universidad Industrial de Santander estudiante de maestría y docente cátedra de la misma universidad.
} 
constantemente la razón de los sentimientos, lo que hace que la nomenclatura pasional, siga siendo un conjunto difuso de palabras. La semiótica dice ante esto que "la sensibilización pasional del discurso y modalización narrativa son concurrentes, no se entienden una sin otra $\mathrm{y}$, sin embargo, son autónomas, probablemente regidas, al menos en parte, por lógicas diferentes" (GREIMAS; FONTANILLE, 2002, p. 21). Lo que muestra que un recorrido narrativo está íntimamente ligado al carácter pasional propio de los sujetos, que pueden ser objeto de análisis de forma separada pero que pertenecen a una misma existencia narrativa.

Además, las pasiones al igual que la cognición y las axiologías son generadores de sentido en un espacio social determinado. Lo que evidencia que los efectos de sentido se capten en cada cultura de forma diferente. Cada cultura determina las formas en las pasiones se proyectan por parte de sus actantes. Así, "la dimensión pasional está esquematizada por la praxis enunciativa y esa esquematización le permite escapar del puro sentir, la hace inteligible y le permite inscribirse en formas culturales que le dan su sentido" (FONTANILLE, 2001, p. 108). Entonces, es importante tener en cuenta que la cultura hace de cada pasión una expresión distinta dotada de rasgos especiales que permiten comprenderla de otras maneras, es decir, dar sentido al universo pasional.

De este modo, las pasiones se articulan en el discurso como un elemento fundamental que da cuenta de los estados de los sujetos a partir de su impresión sensible y a través del reconocimiento cognitivo que se le dé en cada cultura. Al mismo tiempo, ni la cultura ni la pasión están aisladas del cuerpo propio del sujeto que es aquel que modula y orienta las transformaciones en el discurso. Así lo expresa Fontanille cuando afirma que "la intensidad pasional del discurso tiene por correlato fenomenológico la propioceptividad, la sensibilidad del cuerpo propio que sirve de medidor entre los dos planos de la semiosis" (2001, p. 178). Por tanto, la pasión como dimensión hace parte y depende del discurso.

Las pasiones se integran a los constituyentes propios de la identidad discursiva. Puesto que para la semiótica, la identidad "sirve para designar el principio de permanencia que le permite a un individuo seguir siendo el mismo, persistir en su ser, a lo largo de su existencia narrativa, a pesar de los cambios que provoca o sufre" (GREIMAS; COURTÉS, 1990, p. 2012-213) y es en la última dimensión donde los sistemas de valores y las pasiones son ejes fundamentales. Además, Fontanille (2001) asegura que la identidad está compuesta por muchos constituyentes, particularmente por modalidades que son las que le dan la coherencia a los estados y transformaciones de los sujetos, "la pasión podría ser considerada como el principio de la coherencia interna del sujeto. Disocia o moviliza, selecciona un rol y suspende otros, reúne los roles en torno a uno solo [...] rige las relaciones entre sus partes constitutivas" (p. 181). Por lo cual se hará un recorrido modal del discurso, pues esto permitirá dar consistencia al desarrollo pasional posterior.

\section{La ira o cólera}

En la diversidad de pasiones se encuentra la ira, también llamada cólera desde la antigüedad, en la que los sujetos expresaban furia y alta irritabilidad. La ira o rabia según la sicología tiene una gran carga de resentimiento y físicamente, a diferencia de otras pasiones, es visible ante la mirada del otro. Generalmente la ira es acompañada de aceleración cardíaca, color rojo en el rostro, estremecimiento del cuerpo, debido a los altos niveles de adrenalina y neoadrenalina que se reparten en el cuerpo.

Para la psicología, la ira es un sentimiento de descontrol anímico donde hacen presencia la violencia, el enojo, la angustia y la indignación generados entorno a situaciones diversas. También, se refiere la ira como un producto de una falta de amor o cariño. Si este 
sentimiento no es canalizado puede ocasionar daños irreversibles en sí mismo y en otros. Sin embargo, se cree que la ira entendida como un valor de supervivencia puede transformarse en un elemento positivo si es responsable de llevar al individuo hacia una búsqueda de soluciones y posibles factores de ayuda. Lo cual muestra valoraciones tanto disfóricas como eufóricas de esta pasión.

Gergen (1997) habla de la ira como una emoción pero que según Schachter carecía de bases biológicas netamente diferenciadas; "a lo sumo, podía decirse que un individuo afectado por una intensa emoción [...] mostraba una «activación fisiológica generalizada" (GERGEN, 1997, p. 312), pues las personas furiosas experimentan aumento en la tensión arterial, el ritmo cardiaco. Además, este mismo autor aduce que la ira no se debe considerar un impuso biológico desencadenado por frustraciones y en gran medida ajeno al control consciente, sino que recomienda reconceptualizar la ira y verla como una forma: de actuación cultural -sostenida por modelos culturales e insertos en las pautas de relación-. Esta sugerencia desde la sicología muestra el carácter relacional de los desarrollos pasionales

En la religión, la ira ha tenido un espacio central. Específicamente en la religión cristiana, por ejemplo, la ira hace parte de la lista de pecados capitales. Según la teología, la ira puede ser descrita como un sentimiento no ordenado ni controlado de odio y enfado. Reunidos, estos sentimientos, pueden manifestarse como una negación hacía sí mismos y deseando el mal otros. Generalmente hay impaciencia, intolerancia y deseo de venganza. Se habla de que la ira provoca suicidios, asesinatos y en casos extremos genocidios (ASTETE, 1992). La ira es el único pecado que no necesariamente se relaciona con el egoísmo y el interés personal aunque se puede tener ira por egoísmo. Otras religiones como el Islam ven la ira como muestra de debilidad, así como el hinduismo dice que el fuerte no es el que supera gente por su fuerza, sino que fuerte es el que se controla mientras sufre de ira. En la misma línea, el budismo afirma que los objetos de ira se perciben como obstáculos para la satisfacción de los deseos de la persona enojada.

Por su parte, la filosofía ve la ira como deseo y no como facultad de castigar. Muchos autores se han referido a esta pasión. Séneca en De la ira (1999) afirma que no hay un individuo tan humilde que no pueda esperar vengarse hasta del más encumbrado. La definición de Aristóteles, citado por Séneca, no se separa mucho de esta, porque se refiera a la ira como el deseo de devolver el daño. Espinosa también explica que no menos que los afectos de amor, los hombres están sujetos a los afectos del odio, entendiendo por tales el grupo de "la envidia, la irrisión, el desprecio, la ira, la venganza y los restantes afectos que se remiten al odio o nacen de él" (ESPINOSA, 1980, pág. 220). También este autor relaciona la ira con la superstición al decir que esta última se mantiene por la primera, puesto que no tiene su origen en la razón sino exclusivamente en la pasión más poderosa.

De las anteriores aproximaciones, es clave sintetizar que la ira está inextricablemente relacionada con el deseo violento. También, en la mayoría de las concepciones de ira hace presencia una emoción de carácter disfórico acompañado de agresividad. Además, en todos los acercamientos sobre la ira se muestra como un estado pasajero pues se da de forma espontánea y motivado por situaciones específicas; sin embargo, para algunos es un estado que se repite constantemente en aquellos a los que se les denomina iracundos. Solo en una acepción desde la sicología se le valora positivamente a esta pasión, en el resto es valorada de forma negativa acuñándole debilidad, y refiriéndose a esta como un deseo malvado. 


\section{La ira en semiótica}

En semiótica, la ira ha sido denominada comúnmente como cólera. Greimas (1983) hace un estudio sobre esta pasión que titula De la cólera, un estudio de semántica léxica. En él, hace unas aproximaciones de la progresión de esta pasión a través de una secuencia inicial compuesta por: frustración-descontento-agresividad. Sin embargo, en el diccionario de pasiones literarias (RALLO, 2005), este esquema canónico de la cólera es ampliado, lo cual genera un complemento en la secuencia establecida.

La cólera ha sido analizada desde la premisa de ser una pasión compleja distinta a la avaricia; reconocida como una pasión simple, pues hace parte de las pasiones relacionadas directamente con los objetos. A partir de esta última, se construyó el modelo de análisis de pasiones con unidades sintagmáticas más autónomas, lo que permitió recomponer una configuración pasional que diera cuenta de una definición de pasiones como la cólera.

En semiótica, la cólera se define como un proceso organizado que forma una secuencia donde todas las etapas son necesarias para la identificación de la pasión, lo que desencadena la conformación de un esquema pasional para esta pasión (Ver figura 1). El esquema secuencial permite observar la progresión y allí se vislumbran las causas y los alcances que puede tener en este caso la ira. En la mayoría de los estudios se le da prioridad a la confianza rota por lo cual la cólera se remonta inicialmente a un contrato fiduciario 2 roto, es decir, se rompe una puesta en juego de "un hacer persuasivo por parte del destinador y en compensación la adhesión del destinatario" (GREIMAS; COURTÉS, 1990, p. 174). Lo cual supone que la ira hay una espera fiduciaria que no es compensada, lo cual genera la segunda etapa que es la frustración, es decir, la espera crea el simulacro de una conjunción virtual a un objeto, pero no actualizarse dicho estado se produce un estado de frustración que es una disjunción virtualizada pues se rompe el contrato al no contar con el objeto valor que creía contar el sujeto. Así, el sujeto frustrado entre en una etapa de descontento que causa una reacción agresiva.

\section{Confianza $\rightarrow$ Espera $\rightarrow$ Frustración $\rightarrow$ Descontento $\rightarrow$ Agresividad $\rightarrow$ Explosión}

Figura 1. Esquema pasional canónico de la cólera

Atendiendo a especificaciones de la filosofía se añade al esquema la explosión, que cumple la función de "descarga" inmediata y muy precoz de la agresividad. Este elemento en el esquema es muy importante pues el concepto de agresividad no necesariamente implica acción, puesto que, según su definición en el DRAE3 (2002), se constituye como una tendencia a provocar violencia. Y una tendencia no garantiza la explosión que el iracundo generalmente muestra cuando está cautivado de esta pasión, solamente su propensión, por lo cual la etapa de explosión resulta clave en el análisis. Rallo (2005, p. 63) explica que:

\footnotetext{
${ }^{2}$ El contrato fiduciario es un contrato enunciativo (o contrato de veridicción) que garantiza el discursoenunciado; si el contrato fiduciario sanciona un programa narrativo en el discurso, se hablará entonces de un contrato enuncivo (GREIMAS; COURTÉS, 1990, p. 174).

${ }^{3}$ Diccionario de la Real Academia de la lengua Española.
} 
La secuencia de la cólera declina la significación de un comportamiento desbordado, estallante, o perturbador generalmente, es la forma misma de la secuencia de una pasión que libera el sentido de la emoción o del comportamiento en los cuales esta se manifiesta (RALLO,

La semiótica también ha podido explorar en la pasión de la ira además de un esquema propio a partir de las relaciones interactanciales, las posibles variantes de la secuencia discursiva y sus respectivos antecedentes. Entre estas variaciones se encuentra la impaciencia. Este concepto podría reemplazar de cierta manera la confianza implícita que puede existir antes de empezar el esquema canónico para esta pasión. La impaciencia puede constituir un detonante inicial para que se genere la ira. Otras variantes que incluye esta pasión son: la desesperación o la indignación, el resentimiento, el enfado (enfurruñamiento), el posible sentimiento de odio y los deseos de venganza.

\section{La ira de Gabriela}

En la crónica Golpes de la vida (ARARAT, 2010), se analiza la secuencia pasional que desarrolla Gabriela, actor femenino principal teniendo en cuenta el esquema canónico ya expuesto así como el dispositivo modal que engloba el discurso. Se debe aclarar que, de la totalidad del discurso, esta parte del texto especialmente constituye una experiencia pasional que puede ser seguida con la secuencia canónica enunciada. Previo a esto, es necesario identificar estructuras narrativas que ubiquen la situación para comprender mejor el fenómeno y en seguida estructuras temáticas que permitan el acercamiento al dispositivo pasional.

En la crónica Golpes de la vida, la secuencia pasional que desarrolla Gabriela, actor femenino principal. Se pretende mostrar cómo actúa el dispositivo pasional en la construcción de la identidad de la actora femenina central, constituyéndose así como una identidad transitoria en pro del cambio de estado del sujeto femenino. Esta crónica cuenta la vida de una mujer colombiana maltratada por su esposo y, en la secuencia específica de la que parte el análisis, Gabriela reacciona frente a la agresión. A continuación el fragmento donde se destaca el componente pasional:

Esa mañana habíamos discutido por cualquier bobada que en este momento no es importante recordar. Mi hermana, Sonia, ese día vino a visitarme a escondidas de mi marido porque a él no le gustaba que yo recibiera visitas, y menos si mi hermana venía acompañada de su novio. Según mi esposo era hombres que ella me traía, por lo que él prefería que me quedara a solas en casa cuidando de los niños y ejercitando mi papel de ama de casa y esposa. Ese día Sonia me trajo como regalo una torta.

Esa tarde, al llegar de trabajar y sin darse cuenta, le pidió a la empleada que le sirviera una porción y, después de comerse el primer bocado, cayó en cuenta de que él no la había comprado y que yo tampoco pude haberlo hecho porque ni trabajaba, ni él me daba plata. Como no nos estábamos hablando por la discusión de esa mañana, le preguntó a mi hija quién la había comprado. Ella, con tan solo seis añitos, ya conocía el temperamento de su papá y al oírlo gritar preguntando quién había traído la torta, empezó a temblar sabiendo que tenía mentir sobre la presencia de otro hombre en nuestra casa. Pero su hermanito, de tan sólo cuatro añitos, no estaba al tanto 
de lo que ocurría y con total inocencia respondió que había sido el tío Martín. En ese instante mi marido la cogió contra la niña, empezó a gritarle y la mandó a dormir sin comer.

A mí eso me apreció un crimen por lo que yo la cargué y la llevé a su cuarto. Él trató de arrebatármela pero yo no lo dejé: mi niña temblaba del susto. Después de dejarla me dirigí a la cocina para servirle un plato de comida y llevárselo a la habitación. Y cuando ese hijueputa vio lo que estaba haciendo, me metió un puño en el ojo izquierdo que me tiró al suelo. Inmediatamente empecé a sangrar y mis dos hijos corrieron hacia mí para ver qué había pasado. Mi reacción fue de histeria. No podía creer lo que ese imbécil acababa de hacer. Al oír los gritos, una de mis vecinas entró y se llevó a los dos niños. En eso yo me paré y me asomé al espejo del baño para ver lo que me había hecho: botaba sangre por la nariz y por el pómulo. Él se paró detrás, burlándose de mí. Yo alcanzaba a verlo a través del espejo, así que lo cogí con la intención de quebrárselo a los pies, pero no calculé, no pensé que estuviera tan cerca y se lo quebré en la cabeza.

Alcanzó a cortarse el brazo derecho y, el muy hijueputa, me denunció ante la Fiscalía, alegando que fui yo quien primero lo atacó. Pero no la supo hacer, pues todos sus alegatos se vinieron al piso ya que si yo lo hubiera cortado primero, él no hubiera podido pegarme en el ojo izquierdo. Al final decidió retirar los cargos (ARARAT, 2010, p.71-72).

En primer lugar, se hallan varios actores que hacen parte del desarrollo narrativo y pasional de la historia, pero son José y Gabriela quienes como sujetos patémicos4 participan activamente de la secuencia pasional. La escena transcurre inicialmente en la sala de la casa y luego en la cocina de la misma. Aun así, el espacio de violencia es constituido por Gabriela, el sujeto enunciador es también construido discursivamente como espacio donde se efectúa el primer acto de violencia, específicamente su rostro. Es decir, el cuerpo como lugar de recepción del golpe, lugar de violencia intrafamiliar "Mi reacción fue de histeria. [...] me asomé al espejo del baño para ver lo que me había hecho: botaba sangre por la nariz y por el pómulo. Él se paró detrás, burlándose de mí" (ARARAT, 2010, p.71). Aquí, se destacan códigos pasionales propios del discurso en acto. Por ejemplo, en el rostro corre la sangre de la víctima, código somático; deja huella el golpe, la herida, que se ve en el espejo que también es un elemento fundamental que proporciona reconocimiento, el reflejo de la burla de la que es víctima. Además, entre los códigos de carácter somático se encuentran los gritos, en el marco de una reacción de histeria.

De este modo, se muestra la importancia del espacio de la configuración pasional, pues es el sujeto patémico al mismo tiempo el lugar donde se concentra la pulsión en la escena. Tanto espacios como actores conforman situación propicia para dar cuenta de los roles actanciales del discurso (Ver figura 2). José es el manipulador, quien pone las reglas y al mismo tiempo el que establece el contrato fiduciario5 implícito de obediencia y abnegación de parte de su esposa, quien a su vez espera un esposo amoroso y buen padre. Gabriela es el sujeto que quiere estar conjunto al objeto que representa el valor del respeto y ante este

\footnotetext{
${ }^{4}$ A diferencia del rol temático ligado al hacer, el rol patémico -llamado también a formar parte del actorconcierne al estar ser del sujeto de "estado". El rol patémico, función del vertimiento tímico del nivel profundo, aparece, en un plano más superficial de representación, como una organización jerárquica modal [...] $C f$. GREIMAS; COURTÉS, 1991, p. 190.

${ }^{5}$ El matrimonio se constituye así en una fiducia.
} 
objeto José se ubica en la posición actancial de antisujeto. También actúa como Destinador judicador cuando sanciona las acciones de Gabriela al regañarla "Tan divino mi esposo como me regaña" (p. 73). Así se representa el esquema actancial.

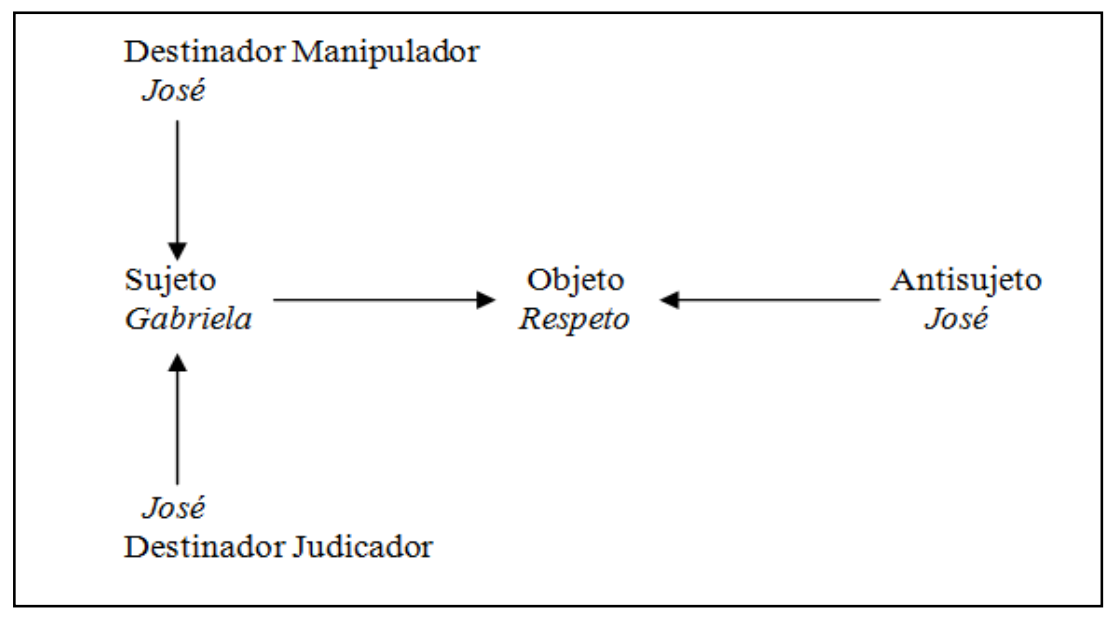

Figura 2.Esquema actancial para la crónica Los golpes de la vida (ARARAT, 2010).

El esquema actancial precedente evidencia los roles actanciales que los sujetos desempeñan. Se hace evidente entonces un sincretismo actancial6 que a la vez que hace hacer a Gabriela (la manipula) una mujer obediente y doméstica al mismo tiempo la juzga sus acciones al castigar a sus hijos por haber dejado entrar a un hombre a la casa; lo que empieza a desencadenar su posición actancial de antisujeto, pues actúa contra el deseo de Gabriela de ser respetada, el deseo de no perder su dignidad como mujer y madre. Este esquema se puede representar también con el programa narrativo de base que sigue Gabriela:

$$
\mathrm{PNb}: \mathrm{S}_{1} \rightarrow\left(\mathrm{S}_{2} \cap \mathrm{O}\right)
$$

Este programa narrativo es la representación de la conjunción que pretende unir a Gabriela con su objeto de deseo, el respeto. Dicho PN moviliza otros programas narrativos de uso tales como desobedecer, ayudar a sus hijos, dar de comer, servir, entre otros. Estos subprogramas muestran al mismo tiempo las modalidades intrínsecas dadas en el discurso, pues son estas acciones las que muestran cómo en cada momento está modalizado el sujeto. "La identidad pasional de los actantes, basada en los valores modales, es, uno de los lugares claves de la interacción entre la identificación de los actantes en el enunciado y los roles y actitudes pasionales" (FONTANILLE, 2001, p. 156). En lo que concuerda con Greimas cuando afirma que desde el inicio del despliegue pasional, es decir, la espera como estado original de la ira, el sujeto no se encuentra en un estado neutro sino en "el estado de un sujeto fuertemente modalizado" (1989, p. 257).

En segundo lugar, se fija la atención en las estructuras modales. Se observa al actor femenino manipulado por un deber ser que se puede suponer es instaurado por el esposo "él prefería que me quedara a solas en casa cuidando de los niños y ejercitando mi papel de ama de casa". Ella se presenta como un sujeto obediente que responde al contrato fiduciario matrimonial, entonces también está modalizada por el querer hacia su marido y hacia sus

\footnotetext{
${ }^{6}$ Se da cuando el mismo sujeto ocupa dos o más roles actanciales.
} 
hijos. Sin embargo, las acciones de José altera el estado de las cosas. Ella, al ver la injusticia de la que son víctimas sus hijos, se ve modalizada por un deber que surge de su saber-sobre el ser buena madre y desobedece la orden del esposo al intentar llevarles comida al cuarto a pesar de la orden dada por José. Ese rompimiento produce la reacción violenta de José. A pesar de eso, Gabriela continúa modalizada por el deber, pues ella no reacciona inmediatamente después de la agresión. Fue necesario ver la burla de parte de él, ver a través del espejo no solo cómo la sangre corría sobre su rostro sino la risa de José, elementos que detonan la ira de Gabriela, es decir, activan el poder que ella siempre ha tenido de hacer lo que no le dicen, un deber no hacer. Esto es, Gabriela actualiza su poder y hace: le quiebra el vidrio en la cabeza, aunque no era su objetivo iba dirigido hacia allá, ella misma afirma no haber calculado el impacto.

El esquema modal muestra que Gabriela está disjunta del respeto, pero ella no es consciente de eso, es la secuencia pasional la que muestra cómo poco a poco va tomando conciencia de que ella no está siendo compensada en el contrato fiduciario que mantiene con su esposo. Puesto que, a pesar de las lesiones sicológicas que José hace sobre la niña especialmente, ella no actúa contra él directamente, es decir, no le reclama. Tan solo en el acto de desobediencia implícita hay una muestra de potencia vs impotencia, puesto que ella no debe hacer un reclamo, porque no está dentro de los cánones de dicho contrato. Sin embargo, el hecho de cuidar a sus hijos a pesar de las órdenes del marido le revela el poder que tiene. Es en este punto donde actúa una especie de frustración de poder que en ese momento no enfrenta directamente. Sin embargo, el golpe que le fue propinado y su reacción de histeria hacen que se incremente su estado pasional y, a través de él, consiga de cierta manera "romper las cadenas".

En este punto, se puede decir que la identidad del sujeto está en vía de transformación, pues ella está siendo modalizada por los efectos que tiene la dimensión pasional. Los afectos trastocan su status quo de mujer abnegada y sumisa, de mujer temerosa de lo que diga y haga su marido. El incremento pasional despierta, dispone y motiva la transformación de la enunciadora. Ella se configura como un sujeto de estado y de hacer impulsado por la pasión que empieza a sentir.

Concretamente, el rompimiento de la fiducia del matrimonio evidencia la transformación de un estado de sumisión que podría verse como un estado de ceguera que pasa a cierta lucidez. Ella observa que no es el hombre que idealizaba, no la regaña porque es un buen hombre que la quiere corregir, es un hombre agresivo. "Cada vez que discutíamos me empujaba y yo tan inocente, o más bien boba, pensaba: 'Tan divino mi esposo como me regaña" contrasta, refiriéndose al golpe, con "No podía creer lo que ese imbécil acababa de hacer [...] él se paró detrás, burlándose de mí". Esto es, un estado 1 se transforma, pasa a un estado 2. El primero modalizado por un deber ser y el segundo modalizado por un querer hacer, pues el tomar consciencia de con quien estaba conjunta, el saber sobre José maltratador le quita el querer estar conjunta a él y le instaura el querer acabar con el dolor que le producen los golpes de los que ahora es víctima. Y ese querer cambiar, ese apasionamiento producido in situ le da poder para hacer "Yo alcanzaba a verlo a través del espejo, así que lo cogí [...] se lo quebré en la cabeza". El sujeto de estado, pasivo, se transforma en sujeto de hacer impulsado por un estado afectivo en sujeto activo.

Un cuadrado semiótico podría representar de una forma más clara las posiciones presentes en esta escena enunciada. Donde el sujeto se encuentra modalizado por el deber ser obediente pero los malos tratos y el general la ruptura del modelo de hombre ideal que ella tenía en sus simulacro, la llevan al acto de rebeldía que la pone en un nuevo estado, un deber no ser que es la desobediencia. Ese estado en su recorrido inverso, la llevaría 
nuevamente a la sumisión que es el paso en el recorrido que la lleva a la obediencia nuevamente. Esta última pareja (obediente y sumisa) representan el carácter de subordinación en el que se encontraba Gabriela. Mientras que la desobediencia y la rebeldía son características de la insubordinación, estado que le brinda el desarrollo pasional de la ira, pues le permite saber y por tanto instaurar un nuevo deber no ser doméstica.

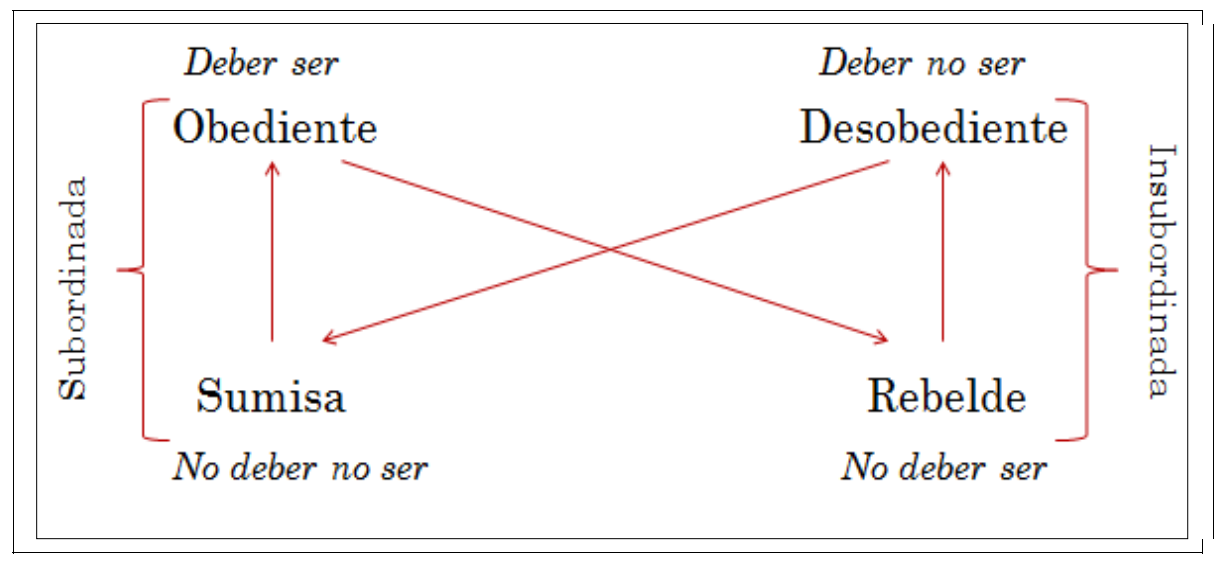

Figura 3. Cuadrado semiótico del deber.

Para dar cuenta detalladamente de la configuración pasional, es necesario evidenciar el perfil de intensidad del sujeto. "La pasión se basa en la lógica de las modulaciones continuas de la intensidad semántica, en relación con la cantidad (sea la cantidad actancial o la extensión espacio-temporal)" (FONTANILLE, 2001, p. 175), puesto que la pasión, como la acción, transforma. Gabriela como actor principal que cumple el rol del actante sujeto, ella es quien presenta sus cavilaciones: "No podía creer lo que ese imbécil acababa de hacer", en forma de exclamación sobre el comportamiento de su esposo al pegarle. La intensidad aumenta cuando en el relato se refiere al marido con insultos: "hijueputa", “imbécil". El primero es repetido en dos ocasiones lo que muestra un aumento en la cantidad pasional. Al mismo tiempo, estas palabras soeces configuran una regulación del discurso.

El principio de regulación del lenguaje constituye a la vez la condición para que los participantes se comprometan en el proceso de reconocimiento del contrato de comunicación y la condición para que el intercambio comunicativo prosiga y culmine. En el caso le permite al sujeto comunicante implementar ciertas estrategias de base, cuya finalidad consiste en asegurar la continuidad o la ruptura del intercambio por: aceptación/rechazo de la palabra del otro y de su estatuto en tanto ser comunicante, valorización/desvalorización del compañero [...] (CHARAUDEAU; MAINGUENEAU, 2005. p. 494).

Entonces, según lo acotado por Charaudeau, los insultos insertos en el discurso de Gabriela cumplen un función regulatoria, precisan el momentos en el que se da paso a un nuevo contrato fiduciario. Esto es, el sujeto femenino está actuando según el simulacro que ella construyó del hombre ideal que junto a sus hijos conforman lo que ella desea: una familia 
ideal en la que haya felicidad, respeto, amor, etc. Es la fiducia del matrimonio instaurada en el imaginario ideal. Esa imagen de hombre ideal se configuró como su objeto de deseo en el momento en el que se enuncia "se sentía muy enamorada de José" y más adelante cuando habla de la felicidad que le produjo irse a vivir con él.

De ese modo, las palabras soeces constituyen el cambio de contrato que se rompe con la explosión. Esas palabras ya no son para el hombre ideal, sino para el hombre que ella no reconocía, aquel que la humillaba y que ahora la golpeó. Este discurso entonces está modalizando ese nuevo contrato, las groserías dan muestra de esa transformación discursiva, de las valoraciones negativas donde se regulan las ofensas, las humillaciones y las agresiones de las dos partes. El discurso de Gabriela cumple dicho principio instaurando una nueva fiducia donde se rompe el simulacro del ideal, del hombre caballero y amoroso, pasa al hombre maltratador y golpeador lo que lleva a cambio del simulacro del sujeto femenino.

La intensidad sigue aumentado con sus gritos, que ella misma denomina reacción de histeria. La histeria, que pertenece al léxico pasional, según el DRAE es una enfermedad nerviosa, crónica, más frecuente en la mujer que en el hombre, caracterizada por gran variedad de síntomas, principalmente funcionales y a veces por ataques convulsivos. La histeria era diagnosticada como enfermedad muy grave en el siglo XVIII, aún hoy es estigmatizada como una enfermedad del género femenino. En este caso, la histeria es solamente la cantidad e intensidad de gritos emitidos por Gabriela en respuesta a la herida provocada por su esposo. Esta histeria mencionada también hace parte del conjunto de códigos pasionales, se encuentra dentro de los códigos rítmicos, pues los gritos son códigos sonoros que ambientan el estado de shock en el que ella entra cuando es golpeada por su marido.

Así, la intensidad continúa aumentado cuando, por medio del espejo, puede ver lo que en una situación distinta a la de crisis y directamente no había podido ver, su risa burlona, maliciosa. Es decir, es el espejo el que le permite ver el contrato fiduciario del que ella era parte tenía una cláusula de sometimiento que ella no había visto de esa manera, la obediencia a cambio de buenos tratos no existía, el rol de esposa abnegada a cambio del rol de buen padre se esfumaba, pero fue su risa de burla la que selló sus dudas, esos aumentos de intensidad. El descubrimiento de que José no era el hombre que ella creía. A pesar de que la hubiera golpeado probablemente él, según el contrato, debía sentirse mal, pero no fue así, él estaba, tal vez sino satisfecho con el golpe, sí gozoso pues se burló del hecho. Se presenta así una puesta en escena del poder de José sobre Gabriela.

En este sentido, un esquema tensivo puede representar la tensión de Gabriela en su despliegue pasional. Se ubican entonces los ejes de tensión el querer en la mira, pues es la parte sensible y el deber en el eje de la captación por ser lo exteroceptivo. Lo que capta, es decir la extensidad frente a lo que va sintiendo se ubica en la mira. La ira va aumentando por lo cual la captación se va concentrando a partir de las actuaciones de José. Primero se encuentra su amedrentamiento hacia no recibir hombres en la casa, lo cual marca desde el principio una predisposición, pero de una forma difusa, sigue aumentando cuando José maltrata a sus hijos, luego cuando la grita, la insulta, la golpea y finalmente se burla de ella. En ese punto se concentra una sinrazón sobre las consecuencias del ensimismamiento pero al mismo tiempo la acumulación de captación en este caso de carácter disfórico, la impulsan a desplegar en su máxima potencia la ira. Y es ahí donde Gabriela se estalla de ira, donde la pasión sube de forma exponencial y actúa golpeándolo, por tanto, el esquema tensivo es de carácter ascendente: 


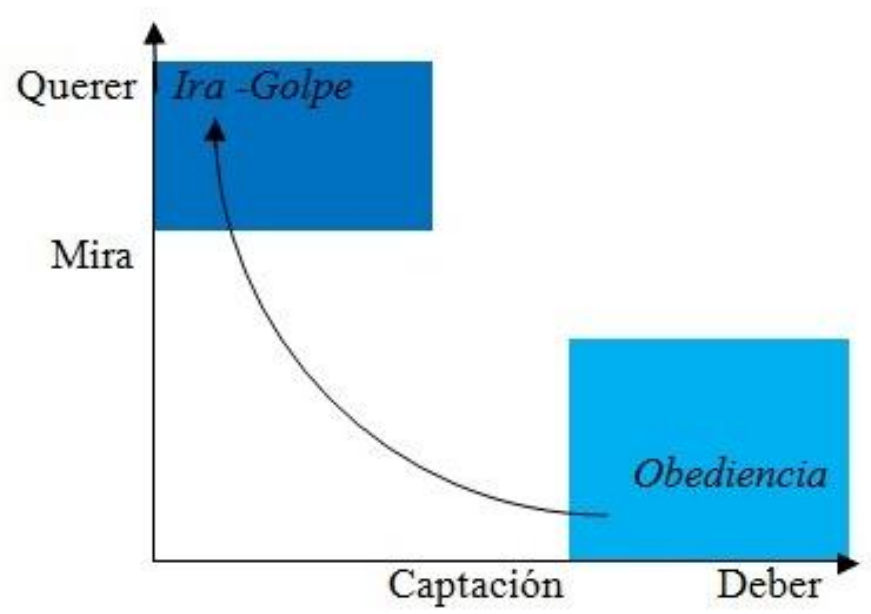

Figura 4. Esquema tensivo de la ira del sujeto patémico.

El exponente pasional de la cantidad afecta a los participantes del despliegue, sean estos sujetos, objeto y situación espacio temporal. Según Fontanille hay casos en los que la "pasión 'recorta' el objeto en partes, para retener algunas y ocultar otras" (2001, p. 180). Por ejemplo, la ira actúa de esta manera en la medida en que moviliza a Gabriela, pues ella selecciona el rol de mujer herida, ofendida, humillada y en ese momento suspende el de madre y esposa abnegada. Asimismo la ira recorta la realidad del hombre que ella veía como querido esposo lo transforma en enemigo. Es decir, el sujeto ha focalizado en ciertos aspectos (su risa burlona) y ocultado otros (que es responsable con llevar dinero a la casa, por ejemplo) porque toda su atención se dirige a las 'partes' seleccionadas.

No obstante, y a pesar de que la ira constituye un ensimismamiento del parte del sujeto patémico, se podría pensar que en la medida en que aumentan las ofensas de parte de José: “[...] me metió un puño en el ojo izquierdo que me tiró al suelo [...] Él se paró detrás, burlándose de mí" (ARARAT, 2010), es decir, la extensidad se amplía, la ira en Gabriela va formándose. De tal suerte que el esquema tensivo arrojaría una tendencia amplificativa. Sin embargo, el hecho de que el esquema que explica de una forma más precisa el enunciado es el de ascendencia, puesto que es el deber la variable que se encuentra en el eje de captación y es el deber el que se obnubila en el momento cúspide del despliegue pasional y la captación se concentra.

Además, el relato deja huellas de un momento de silencio, en el que ella queda absorta, está ella sola viendo sus heridas, observando la sangre que corre por su ojo y su pómulo izquierdo, es decir, aumentando su estado pasional, la histeria en la mitad del recorrido se concentra en sí misma, ya no grita y es escuchada por otros (hijos, vecinos). Esos gritos se transforman en silencio para los de afuera y en gritos para sí, que detonan con lo que ella misma ve a través del espejo, la burla de José, el regocijo de éste al verla degradada, desecha.

Además, la risa burlona sumada a los insultos hacen parte de la regulación discursiva de cada actor y al mismo tiempo la primera hace parte de la cadena de manipulación por intimidación y provocación de la que es víctima Gabriela. José manipuló a Gabriela, primero con los niños luego hizo que ella se cuestionara sobre el marido que tenía "no podía creer lo que ese imbécil hizo" y finalmente se burla de ella a través del espejo y ese 
detonante rompe la línea discursiva, se genera la ruptura de la que habla Charaudeau, pues se aparta el lenguaje y se recurre al acto físico del golpe.

Se puede postular en este punto un cuadrado semiótico de la veridicción, en el cual se sintetiza de forma ilustrada el proceso que lleva a cabo Gabriela con su disposición del querer que se transforma en el desarrollo de la pasión de la ira. Se encuentra un sujeto femenino ubicado en la mentira o en un estado ilusorio, pues ve en su esposo un hombre ideal, buen padre y esposo, es decir, se hace presente un parecer mas no un ser; asimismo ella encuentra como falso cuando la golpea, un hombre maltratado que no parecía entonces un hombre ideal que no era. De tal suerte ella puede reconocer después del episodio el secreto en el que él la tenía, donde él es un hombre real aunque ella no lo pueda creer, lo que finalmente le revela al hombre verdadero que es y parece cuando se burla de ella tras el espejo.

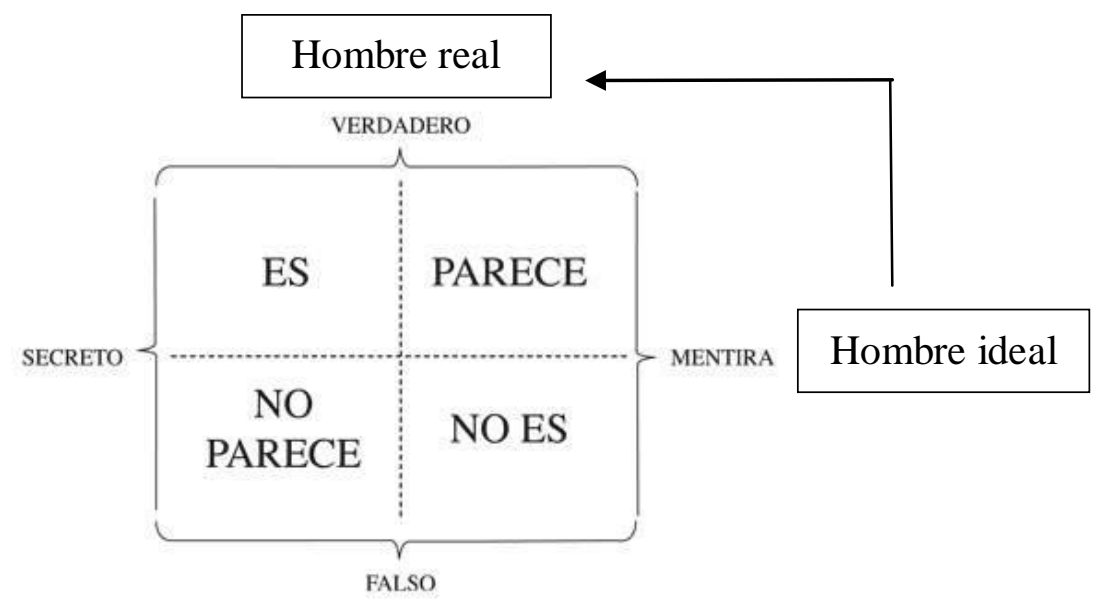

Figura 5. Cuadrado semiótico de la veridicción.

\section{Esquema pasional canónico}

Con estos presupuestos anteriores se puede emprender un reconocimiento del esquema pasional que desarrolla Gabriela en la crónica y dispone a la transformación inminente de identidad inicial de mujer doméstica. Ese recorrido de posesión pasional que experimenta el sujeto femenino se puede organizar en el esquema pasional canónico, para integrar al actante con la propioceptividad, es decir enlazar en el cuerpo propio del actante lo sensible y lo inteligible, los dos elementos que convoca Greimas al describir las pasiones como portadoras de efectos de sentido "poder hablar de la pasión es, pues, intentar reducir la distancia entre el 'conocer' y el 'sentir"' (GREIMAS; FONTANILLE, 2002, p. 21).

- Despertar afectivo: Según Fontanille (2001, p. 108) esta etapa inicia cuando el actante es "sacudido", cuando su sensibilidad es despertada. Así, Gabriela presencia la intimidación que José hace sobre sus hijos. "En ese instante mi marido la cogió contra la niña, empezó a gritarle y la mandó a dormir sin comer. A mí eso me pareció un crimen por lo que yo la cargué y la llevé a su cuarto" (ARARAT, 2010, p. 71). Ese es el primer remezón de emociones al que se somete Gabriela, razón por la cual, comienza su despertar hacia la pasión de la ira. Como muestra la cita, el despertar es activo, el sujeto acciona frente a la situación 
que le es puesta, lo cual está relacionado al encadenamiento entre la acción y la pasión como ejes transformativos, el primero obedece a esquemas narrativos canónicos y el segundo a los esquemas tensivos.

- Disposición: Esta es la etapa en la que se forma el escenario que provocará la pasión. Es un momento de precisión, de disposición frente a lo que inducirá placer o sufrimiento. Gabriela experimenta la indignación. "A mí eso me pareció un crimen. Esta disposición está íntimamente relacionada con despertar afectivo, porque es causa efecto. La injusticia que fue para ella el maltrato sicológico que José ejerció sobre su hija la hace reaccionar ipso facto atendiendo a su hija, brindándole el cariño y los cuidados que en ese momento el padre le niega. La disposición en esta casa está relacionada por la desobediencia a causa de la indignación provocada. En ese momento, su acción va encaminada a subsanar la injusticia; es una formación de la imagen pasional, ya hay en este punto un impulso.

- Pivote pasional: se trata de una transformación de la presencia y no de una transformación narrativa en sentido estricto (FONTANILLE, 2001, p.109). En el pivote, se desarrolla ya el rol pasional, Gabriela es golpeada por su marido: "Y cuando ese hp vio lo que estaba haciendo, me metió un puño en el ojo izquierdo que me tiró al suelo. Inmediatamente empecé a sangrar [...] Mi reacción fue de histeria”. El estado de desobediencia, de cierta manera silenciosa (puesto que ella no le reclama nada al esposo) ayuda a sus hijos, sin gritarlo ni ofenderlo verbalmente. Sin embargo, para José la ofensa es suficiente con desafiar su autoridad al quebrantar su orden de mandar a su hija sin comer a su cuarto. Esta escena violenta, provocada por la ira exacerbada del actor masculino, deja tirada en el suelo a Gabriela, es decir, en una posición inferior a la de su marido, ella ya está abajo y él sobre ella. Es esa histeria sumada al hecho de verse sangrar y ver cómo José se burla de su situación (ahora evidenciada como inferior a él) lo que desencadena la emoción.

- Emoción: es la reacción observable de los actores ante la pasión desbordada. Dice Fontanille que "No se trata de dar sentido a un estado afectivo, sino, sobre todo, de expresar el acontecimiento pasional, de hacerlo conocer, a sí mismo y a los otros" (2001, p. 110). En este caso, el escenario dado en el pivote desencadena la consecuencia observable, que el acto de quebrarle el espejo en la cabeza a su esposo. El texto lo destaca

[...] me asomé al espejo del baño para ver lo que me había hecho: botaba sangre por la nariz y por el pómulo. Él se paró detrás, burlándose de mí. Yo alcanzaba a verlo a través del espejo, así que lo cogí con la intención de quebrárselo a los pies, pero no calculé, no pensé que estuviera tan cerca y se lo quebré en la cabeza (ARARAT, 2010, p. 72).

En el momento más alto de la ira, ella no ve otra opción que de cierta manera vengarse. Ella intenta de cierta manera equilibrar la cargas, darle de lo mismo que ella recibió: golpes y ve en su mano un instrumento como el espejo que sirve para desquitarse no solo de la agresión sino de la burla de su marido de la que es objeto, al verla disminuida, sangrante, herida. 
- Moralización: Es la evaluación que el actor hace sobre la pasión que ha experimentado. Gabriela, tal como se planteó en la emoción evalúa de forma positiva el golpe que producto de su ira le dio a su marido. Ella ve que es una redistribución de las cargas, tanto que ella misma analiza que no le quería pegar en la cabeza que fue un 'mal cálculo'. A esto, se suma la evaluación de afuera que la Fiscalía, como ente regulador en Colombia, media, sin juzgar pero sí pone la visiones del hecho sobre la mesa.

\begin{abstract}
Alcanzó a cortar el brazo derecho y, el muy hp, me denunció ante la Fiscalía, alegando que fui yo quien primero lo atacó. Pero no la supo hacer, pues todos sus alegatos se vinieron al piso ya que si yo lo hubiera cortado primero, él no hubiera podido pegarme en el ojo izquierdo. Al final decidió retirar los cargos (ARARAT, 2010, p. 72).
\end{abstract}

Esta reflexión, que como enunciadora del relato realiza Gabriela, expone también su visión de los hechos que ve en el golpe con el espejo un acto de justicia contra la humillación, la ofensa y la agresión de la que fue objeto. Así, la Fiscalía, de cierta forma, le da la razón y el mismo José viéndose probablemente acorralado decide retirar los cargos. Esa moralización contrario a culpabilizar al sujeto por el estallido de ira con agresividad, lo que hace es estimularla. Por lo menos difunde en la comunidad, contribuye a su énfasis y a su generalización.

En síntesis, la cólera, al haber sido muy estudiada por los teóricos de la semiótica, ha suscitado un esquema canónico pasional particular para dicha pasión, como se enunció anteriormente. Este se ha ido transformando, como inicialmente se dijo, pues poco a poco han ido apareciendo variables que se incluyen y que fortalecen cada vez más el esquema. En este sentido, el cuadro siguiente evidencia la progresión sin los detalles ya dados en el esquema pasional canónico general:

\begin{tabular}{|c|c|c|c|c|c|}
\hline Confianza & Indignación & Enfado & Descontento & Agresión & Explosión \\
\hline $\begin{array}{l}\text { Pacto de un } \\
\text { matrimonio } \\
\text { feliz, tener } \\
\text { al marido } \\
\text { contento. }\end{array}$ & $\begin{array}{l}\text { Es una espera } \\
\text { rota por el } \\
\text { 'crimen' de } \\
\text { mandar a su } \\
\text { hija sin comer } \\
\text { al cuarto. }\end{array}$ & $\begin{array}{l}\text { Acompañado } \\
\text { de } \\
\text { resentimiento, } \\
\text { pues no puede } \\
\text { enfrentarse a } \\
\text { él } \\
\text { directamente } \\
\text { (por la } \\
\text { fiducia). }\end{array}$ & $\begin{array}{l}\text { Cuando él la } \\
\text { golpea, es el } \\
\text { detonante del } \\
\text { odio que } \\
\text { empieza a } \\
\text { sentir, "No lo } \\
\text { puedo creer". } \\
\text { Se acrecentó } \\
\text { con la burla. }\end{array}$ & $\begin{array}{l}\text { Es la } \\
\text { respuesta } \\
\text { agresiva } \\
\text { que ella } \\
\text { tiene. La } \\
\text { tendencia } \\
\text { a } \\
\text { enfrentarse } \\
\text { al otro. }\end{array}$ & $\begin{array}{l}\text { Es el golpe } \\
\text { del espejo } \\
\text { contra el } \\
\text { cuerpo de } \\
\text { José que le } \\
\text { causa } \\
\text { heridas en el } \\
\text { brazo. }\end{array}$ \\
\hline
\end{tabular}

Figura 6. Tabla que se lee en dirección derecha izquierda con las variantes del esquema pasional canónico para la cólera ajustadas al corpus Los golpes de la vida. 


\section{Conclusiones}

La ira como pasión en el corpus analizado resulta ser clave en el desarrollo de la interpretación. Si no se descubre y se organiza el entretejido de dicha pasión el recorrido interpretativo carecería de sentido. El reconocimiento del sujeto patémico y de su modalización a lo largo del discurso, permite además reconocer las potencialidades del sujeto: desmiente el imaginario de la mujer impotente y totalmente sumisa. Puesto que el análisis arroja que ella sí tiene saber y poder, solo que no han sido activados a causa de una espera dada por un contrato fiduciario del matrimonio que tiene implícitas reglas que ella no ha decidido romper, porque no es consciente de ellas, simplemente las vive y asume su miedo como parte natural de su convivencia familiar.

En este sentido, la pasión actúa como eje articulador que la hace reaccionar, es una toma de conciencia, un hacerse saber a sí misma que está sobremodalizada por el deber y esto la hace ver y de cierto modo sentir el sufrimiento que padece. Así, el análisis evidencia que el sujeto femenino de la crónica al estar modalizado por el deber, desconoce sus capacidades de reclamar por sus derechos, de hacerse respetar, de no temer. En este caso fue necesario tocar fondo para darse cuenta del sujeto con quien estaba interrelacionándose, el padre de sus hijos.

Asimismo, la transformación identitaria se hace más clara con el estudio pasional, pues permite ver el desarrollo y las valoraciones que el sujeto patémico le da específicamente a la situación de crisis. Es decir, el estallido de la pasión resalta que la identidad de la mujer doméstica tiene dificultades en su proceso de realización. Por lo cual, la valoración positiva del deber-hacer y su estado de sumisión, de silencio y abnegación cambia para ser valorado con disforia, pues los deseos de violencia y la constatación de parte de Fiscalía que hace efecto por omisión, no solo moralizan los acontecimientos sino que revalorizan eufóricamente la acción de Gabriela.

\section{REFERÊNCIAS}

ARARAT, L. Los golpes de la vida. In: KREMER, H., El cinturón de fuego y otras crónicas caleñas. Santiago de Cali: Universidad Icesi, 2010. p. 71-77.

ASTETE, P. Catecismo básico. Bogotá D.C.: San Pablo, 1992.

ESPINOSA, B. Ética demostrada desde un orden geométrico. Madrid: Editora Nacional, 1980.

FONTANILLE, J. Semiótica del discurso. Lima: Editorial Universidad de Lima, 2001. ; ZILBERBERG, C. Tensión y significación. Lima: Universidad de Lima, 2004.

GERGEN, K. El yo saturado. Dilemas de la identidad en el mundo contemporáneo. Barcelona: Paidós, 2006.

GREIMAS, A. J. De la cólera. In: Del sentido II. Ensayos semióticos. Madrid: Gredos, 1989. Semiótica de las pasiones. México D. F.: Siglo XXI Editores S.A., 1994.

.; COURTÉS, Joseph. Semiótica. Diccionario razonado de la teoría del lenguaje.

Tomo I. Madrid: Gredos, 1990.

Madrid: Gredos, 1991.

Semiótica. Diccionario razonado de la teoría del lenguaje. Tomo II.

REAL ACADEMIA ESPAÑOLA. Diccionario de la lengua española. Vigésima segunda edición. Madrid: Espasa Calpe, 2002.

RALLO, E. ; FONTANILLE, J.; LOMBARDO, P. Dictionnaire des passions littéraires. Paris: Editions Belin, 2005. 
CASA, Vol.11 n.1, julho de 2013

SÉNECA, L. A. De la ira. Disponible en: http://es.wikisource.org/wiki/De_la_ira:_Libro_ primero

Recebido em: 17.03 .13

Aprovado em: 20.05.13 